\title{
Dialetologia: a Dimensão Espacial da Variação Linguística
}

\author{
Dialectology: the space dimension of linguistic variation
}

\author{
Leandro Silveira de Araujo ${ }^{1}$
}

Universidade Federal de Uberlândia

\begin{abstract}
- RESUMO: O presente trabalho visa introduzir o estudante à disciplina que se ocupa da variação dita horizontal, isso é, das variações de uma língua nos muitos espaços geográficos em que ela é falada. Para tanto, o estudo define o conceito de dialeto, mostra sua relação com o âmbito social da linguagem e apresenta quais são "O sentido e as tarefas da Dialetologia" (COSERIU, 1982). Nesse percurso, discutem-se assuntos importantes à área, tais como os conceitos de isoglossas, de irradiação linguística, de geografia linguística, dos mapas linguísticos e da relação da Dialetologia com outras disciplinas, como a Sociolinguística.
\end{abstract}

- PALAVRAS-ChAVE: Dialetologia. Geografia linguística. Dialeto. Variação diatópica.

- ABSTRACT: This paper aims to introduce the student to the discipline that deals with the horizontal variation, that is, variations of a language in many geographic areas in which it is spoken. Therefore, the study defines the concept of dialect, shows its relationship to the social scope of language and presents what are the sense and tasks of Dialectology (COSERIU, 1982). In this path, we discuss important issues to the area, such as the concepts of isoglosses, linguistic irradiation, linguistic geography, linguistic maps and Dialectology's relationship with other disciplines, as Sociolinguistics.

- KEYWORDS: Dialectology. Linguistic geography. Dialect. Diatopic variation.

\section{Para começar, o que é dialeto? ${ }^{2}$}

"El dialecto es lo que uno es, el registro es lo que uno hace". Com essas palavras, Leonor Acuña, catedrática da Universidad de Buenos Aires, levava a cabo o décimo quarto congresso brasileiro de professores de espanhol, na cidade de Niterói, estado do Rio de Janeiro. Proveniente de uma discussão sobre o ensino da heterogeneidade linguística do espanhol, o fragmento introduzido apresenta a

\footnotetext{
${ }^{1}$ Doutor em Linguística e Língua Portuguesa pela Universidade Estadual Paulista (UNESP/Araraquara) e Professor Adjunto no Instituto de Letras e Linguística (ILEEL) da Universidade Federal de Uberlândia (UFU). Email: araujoleandrosilveira@gmail.com

2 Esta breve discussão tem como principal objetivo introduzir o leitor iniciante nos estudos da dialetologia, sem se preocupar em trazer grandes questionamentos inovadores à disciplina.
} 
preocupação da conferencista em assinalar como proceder ao estudo da língua tendo em vista uma escala de especificação que vai desde um nível de observação mais genérico e abstrato - encontrado, por exemplo, no conceito de língua histórica -, avançando, de maneira mais específica, pelo nível do dialeto e, finalmente, culminando no registro, isto é, no uso efetivo e individual que fazemos da linguagem.

Deste modo, parece que, para Leonor Acuña, o âmbito dialetal, apesar de mais específico, ainda envolve algum tipo de abstração que permite identificar e associar um enunciador a uma comunidade de fala. Por sua vez, essa identificação partiria do registro, isto é, do uso que cada um faz da língua e no qual se verificam traços linguísticos compartilhados por uma variedade espacial de dada língua histórica. A compreensão do dialetal deveria partir, portanto, da observação do registro.

Ao encontro das palavras de Leonor Acuña, Lope Blanch (1998) não comenta se o âmbito dialetal envolve algum grau de abstração, mas verifica nele um alto grau de concretude, isso porque se trataria do próprio uso efetivo que cada falante faz da língua (sistema). Tanto é assim que equipara o conceito de dialeto ao conceito de fala (registro) e, em seguida, diferencia-os de língua:

[...] dialecto o habla es la manera en que el individuo o la sociedad realiza hacen uso real - (d)el sistema. Es decir que la lengua, el sistema lingüístico en abstracto, se materializa y vive a través de sus dialectos. Todo acto de habla, de comunicación lingüística, será un hecho dialectal (LOPE BLANCH, 1998, p.45).

Apesar de um tanto particulares, ambas as posturas compartilham a definição de dialeto a partir do confronto do termo com o conceito de língua. Esse procedimento, recorrente dentro dos estudos dialetológicos, é também realizado por Coseriu (1982) em seu clássico trabalho sobre o Sentido e tarefas da dialetologia. Nessa obra, observa-se que uma língua histórica "não é um modo de falar único, mas sim uma 'família' histórica de modos de falar afins e interdependentes",; por sua vez, "os dialetos são membros desta família ou constituem famílias menores dentro da família maior" 5 ". Em poucas palavras, a ideia de língua histórica parece pressupor fundamentalmente a existência de uma língua comum que recobre um conjunto de dialetos que, como concretização da língua histórica, mostra alguns dos traços previstos no sistema abstrato maior. Tanto é assim que Weinreich, Labov e Herzog (2006, p.100) comentam que a língua pode ser vista "como um 'diassistema' composto de dialetos-membros".

Coseriu (1982) lembra ainda que uma língua histórica realiza-se somente por meio de suas variedades - tidas como microssistemas autossuficientes - e que, portanto, não falamos o "espanhol" ou o "português", mas fazemos uso de uma parte específica dessas línguas, isto é, de suas variedades. Há de se observar, no entanto, que a variedade geográfica - também chamada de variedade "horizontal" - não é a única variação que ocorre nas línguas históricas, isso porque, como observam, entre outros, Chambers e Trudgill (1994), Coseriu (1982), Ferreira e Cardoso (1994), junto às variações espaciais (diatópicas), observam-se diferenças de nível sociocultural (diastráticas), de gerações

\footnotetext{
${ }^{3}<$ Tradução nossa> "[...] dialeto ou fala é a maneira pela qual o indivíduo ou a sociedade realiza - fazem uso real - (d)o sistema. Ou seja que a língua, o sistema linguístico abstrato, materializa-se e vive através de seus dialetos. Todo ato de fala, de comunicação linguística, será um fato dialetal" (LOPE BLANCH, 1998:45).

4 "[Una lengua histórica] no es un modo de hablar único, sino una "familia" histórica de modos de hablar afines e interdependientes" (COSERIU, 1982:12).

5 “[...] los dialectos son miembros de esta familia o constituyen familias menores dentro de la familia mayor." (COSERIU, 1982:12).
} 
(diacrônicas), de estilo (diafásicas), entre outras. Atentos a esses diferentes âmbitos de variação, Chambers e Trudgill $(1994$, p. 82) concluem que "todos os dialetos são tanto espaciais quanto sociais, posto que todos os falantes têm um entorno social da mesma maneira que uma localização espacial ${ }^{6, "}$.

No entanto, visando melhor apurar a percepção de que tanto os aspectos socioculturais como os espaciais podem confluir no termo dialeto, Coseriu (1982) alerta que "os dialetos 'espaciais' [...] são geralmente sistemas 'completos' sob o ponto de vista fônico, gramatical e léxico ${ }^{7 "}$, possuindo, inclusive, variações sociais e estilísticas próprias. É diante dessa relativa complexidade verificável nas variedades espaciais que o autor categoricamente atribui a observação das diferenças geográficas ao termo dialeto, sendo as variações estilísticas e sociais compreendidas dentro desse microssistema. Neste sentido, o dialeto passa a ser entendido, segundo Coseriu (1982), como uma língua funcional, pois, "dentro de uma língua histórica, é um sistema autossuficiente mínimo", no qual os fatos linguísticos "funcionam precisamente em oposições funcionais internas 9 ". Do mesmo modo, nós, orientados pelo referencial apregoado pela disciplina, conceberemos dialeto como um sistema funcional de caráter mais concreto que, por sua vez, encaixa-se em um sistema maior e mais abstrato que é a própria língua histórica. Assumindo essa postura, afastamo-nos da concepção de dialeto frequentemente difundida pelo senso comum, segundo a qual se atribui uma carga negativa ao termo, tratando-o como uma alusão a uma língua menor, que, de tão desprestigiada socialmente, sequer desfrutaria do status de língua histórica.

\section{Mas o que tem de social o Dialeto?}

Ainda sobre a atenção dada à variação geográfica nos estudos do dialeto, Caravedo (1998) explica que a relação existente entre língua e espaço pode ser compreendida de maneira abrangente (lato) ou específica (stricto). A primeira mostra que as línguas, graças a seu caráter social, estão localizadas em espaços determinados tal qual seus falantes, de modo que "não há forma de se referir à manifestação social de uma língua se não for em relação a seu assentamento geográfico ${ }^{10}$ ". Por outro lado, em uma perspectiva mais restrita (stricto), a partir da análise de fenômenos linguísticos específicos, podemos averiguar que "o espacial pode se converter em um fator de variação da mesma maneira que o social ${ }^{11 "}$. É inserido nessa perspectiva que se associa, por exemplo, o fone fricativo dental surdo $[\theta]$, nos grafemas " $\mathrm{z}$ " $\mathrm{e}$ "c" das palavras "zapato" e "cebolla", a variedades peninsulares do espanhol e o fone fricativo alveolar [s], nos mesmos contextos fonológicos, a variedades americanas. Em outras palavras, sob uma perspectiva restrita, determina-se o fone variante da variável $[\theta]$ e $[s]$ conforme a observação da variedade espacial. Esse é o caso também da distribuição do pronome pessoal no espanhol e no português. Se pensamos novamente no espanhol, o pronome

\footnotetext{
6 "Todos los dialectos son tanto espaciales como sociales, puesto que todos los hablantes tienen un entorno social igual que una localización espacial.” (CHAMBERS; TRUDGILL, 1994:82).

7 "[...] los dialectos "espaciales" [...] suelen ser sistemas "completos" desde el punto de vista fónico, gramatical y léxico [...]” (COSERIU, 1982:24).

8 "[...] dentro de una lengua histórica, es un sistema autosuficiente mínimo" (COSERIU, 1982:20)

9 "[...] los hechos lingüísticos [...] funcionan precisamente en oposiciones funcionales internas [...]" (COSERIU, 1982:32).

10 "No hay forma de referirse a la manifestación social de una lengua sino respecto de su asentamiento geográfico." (CARAVEDO, 1998:78).

11 "[...] lo espacial puede convertirse en un factor de variación de la misma manera que lo social." (CARAVEDO, 1998:78).
} 
pessoal de segunda pessoal do plural "vosotros" está limitado espacialmente a variedades do espanhol peninsular.

Assim, a partir da compreensão favorecida pela análise abrangente (lato) - de que os espaços em que se manifestam as línguas são entendidos como espaços geossociais, isto é, que se desenvolvem em entornos sociopoliticamente determinados podemos entender porque, em uma perspectiva mais restrita (stritus), "as línguas podem variar tendo como fatores condicionantes, além de outros, o espacial, como diferenças de zonas ou regiões, ou o social, como diferenças de grupo"12. É importante enfatizar que a percepção estrita só pode ser compreendida se estiver pressuposta a ideia de espaço geossocial; isso se deve a que as relações espaciais observadas no sentido restrito "não são concebidas como relações determinantes por si mesmas, mas como relações condicionadas política, social e culturalmente" ${ }^{\prime 13}$.

Uma das evidências de que o social media a relação entre o espaço e a língua pode ser encontrada no modo como se difundem os fenômenos linguísticos no espaço. Assim, conforme conferimos na asseveração que segue, a relação de interação linguística instaurada entre indivíduos constitui uma condição inicialmente satisfatória para que se propague uma forma linguística por diferentes zonas.

[...] las formas no "viajan" de por sí, sino que se introducen en el acervo de un individuo a través del habla de otro individuo mediante contactos que no implican una continuidad de áreas, porque los individuos se trasladan de un área a otra con todos sus hábitos lingüísticos, y también a través de contactos indirectos (COSERIU, 1977:157) ${ }^{14}$.

Não obstante, outros fatores podem se somar à relação inter-sujeitos quando o assunto é a difusão espacial de fenômenos linguísticos; esse é o caso, por exemplo, da avaliação que se tem do outro e de sua variedade. Assim, regiões de maior importância social, política e econômica tendem a ser alvo de maior prestígio, favorecendo, por isso, a disseminação dos traços linguísticos que lhes são característicos. Por outro lado, regiões menos relevantes no contexto socioeconômico de um povo tendem a ter seu comportamento linguístico marcado por um estigma que inibe a veiculação de suas características linguísticas a outras áreas. Tanto é assim que Coseriu (1977) afirma que "os centros de irradiação [...] não são os centros geométricos dos territórios estudados, mas os centros políticos, administrativos, culturais e religiosos, os centros comerciais e de comunicação" ${ }^{15}$. No entanto, não podemos cair no equívoco de pensar que somente o prestígio determina padrões linguísticos, tanto é assim que Labov (2008) mostra que nem sempre é a variedade de maior prestigio a responsável pela propagação de novos traços linguísticos. Segundo o autor, classes econômicas mais baixas e estigmatizadas, por exemplo, podem ser agentes nesse processo também.

\footnotetext{
12 “[...] las lenguas pueden variar teniendo como factores condicionantes, además de otros, el espacial, como diferencias de zonas o regiones, o el social, como diferencias de grupo [...]" (CARAVEDO, 1998:79).

13 "[...] no se conciben como relaciones por sí determinantes, sino como relaciones condicionadas política, social y culturalmente" (COSERIU, 1977:106).

14 < Tradução nossa> "[...] as formas não "viajam" por si só, mas se introduzem no acervo de um indivíduo através da fala de outro indivíduo mediante contatos que não implicam uma continuidade de áreas, porque os indivíduos se trasladam de uma área a outra com todos seus hábitos linguísticos, e também através de contatos indiretos" (COSERIU, 1977:157).

15 “[...] los "centros de irradiación" [...] no son los centros geométricos de los territorios estudiados, sino, los centros políticos, administrativos, culturales y religiosos, los centros comerciales y de comunicación [...]" (COSERIU, 1977:106).
} 
Uma breve revisão do que já tratamos nessa seção mostra que, implícita ou explicitamente, dialeto caracteriza-se pela subordinação de um sistema linguístico a outro sistema maior, compreendido como a própria língua histórica. Essa característica pode também ser observada na definição dada por Dubois (1978) para o termo. Segundo o autor, "dialeto é uma forma de língua que tem o seu próprio sistema léxico, sintático e fonético, e que é usada num ambiente mais restrito que a própria língua” (DUBOIS, 1978:184).

Observemos que ao dizer "mais restrito" o autor insere o microssistema dialetal no macrossistema da língua à qual se subordina. É nesse sentido que Montes Giraldo (1987) afirma que o caráter dialetal de um sistema linguístico decorre fundamentalmente de sua subordinação a um sistema maior. O autor também explica que se trata de uma subordinação normativa e funcional que se pode dar em diferentes níveis. Assim, se pensamos nos diferentes níveis de variação idiomática, teríamos, entre língua e registro, três níveis dialetais:

a) Nível do superdialeto: reúne, em um conjunto mais ou menos extenso, variedades que compartilham alguns traços ou normas.

b) Nível do dialeto: variedade incluída dentro de um superdialeto.

c) Nível do subdialeto: divisão do dialeto.

Não obstante, Montes Giraldo (1987) adverte que "esta divisão é sempre subjetiva ou, ainda, dependente das necessidades do objeto de estudo ${ }^{16,}$, e que caberá a cada pesquisador determinar as divisões que convém estabelecer para o procedimento do fenômeno estudado.

Finalmente, o estudo etimológico do termo dialeto feito por Coseriu (1982) mostra que desde o grego clássico atribuem-se à palavra três significados: "modo de falar", "subordinação a uma língua histórica" e "delimitação no espaço". Não obstante, o autor faz a ressalva de que desde então o terceiro valor já era mais recorrente e restrito aos domínios da Dialetologia. A fim de melhor conhecer esta disciplina e suas ocupações, passemos a uma abordagem epistemológica.

\section{Dialetologia: sentido e tarefas.}

Cardoso (2010) assinala que o interesse pelo estudo sistemático dos usos linguísticos e a preocupação com a observação das variedades geográficas sempre estiveram presentes na história dos povos seja por simples constatação, seja como um instrumento político ou, ainda, como um mecanismo de descrição das línguas. No entanto, é somente a partir do século XIX que esses estudos sistematizam-se, demonstrando objetivos próprios e metodologia definida por meio da Dialetologia disciplina que "assumiu a tarefa de descrever comparativamente os diferentes sistemas ou dialetos em que uma língua se diversifica no espaço, e de estabelecer os limites" (DUBOIS, 1978:185).

Coseriu (1982) diz haver dois interesses fundamentais para a disciplina. Enquanto o primeiro visa ao "estudo da distribuição espacial das línguas, ou seja, da variedade diatópica e das relações interdialetais", o segundo fundamenta-se em "comparações léxico-gramaticais (gramática comparada) entre as variedades". Observemos que com o primeiro objetivo a disciplina busca estabelecer a extensão das

16 “[...] esta división es siempre subjetiva o, más bien, dependiente de las necesidades del objeto de estudio.” (MONTES GIRALDO, 1987:60). 
variedades espaciais e, por conseguinte, os limites da realização dos fatos linguísticos observados. Por sua vez, o segundo interesse da Dialetologia conduz à observação e ao registro de fenômenos linguísticos espacialmente comparáveis. Em complemento, o autor alerta que para não correr o risco de interpretações equivocadas no cotejamento diatópico de fenômenos linguísticos, deve-se manter o controle das variáveis sociais e estilísticas em uma abordagem como a prevista por essa tarefa da dialetologia. Também definindo os interesses maiores da disciplina, Cardoso (2010:25) destaca dois objetivos: a) "o reconhecimento das diferenças ou das igualdades que a língua reflete" e b) "o estabelecimento das relações entre as diversas manifestações linguísticas documentadas" nos diferentes "espaços e realidades prefixadas".

Em síntese, tanto para Coseriu (1982) como para Cardoso (2010), estão no âmago da disciplina a descrição da diversidade espacial e o cotejamento da realidade linguística nas diferentes zonas. São essas características que fazem da Dialetologia "a ciência da variação espacial, da delimitação dos espaços, do reconhecimento de áreas dialetais, contribuindo para uma visão de dialeto que extirpe preconceitos e seja desprovida de estigmatização" (CARDOSO, 2010:45).

Ainda conforme a autora, os dados levantados por uma abordagem dialetológica devem possibilitar, acima de tudo, a afirmação de que dado fenômeno linguístico é verificável, ou não, em uma região dialetal observada, sem, contudo, ter o compromisso primordial de "definir sua natureza - variação estável ou mudança em curso -, de quantificar seu uso [...] ou de quantificar os fatos segundo o tipo de usuário, levando em conta variáveis sociais [...]" (CARDOSO, 2010:92). Em outras palavras, enfatiza-se mais uma vez o interesse essencialmente comparativo léxico-gramatical vinculado à disciplina desde seus primórdios.

No entanto, como se presume das palavras da autora, apesar de não ser a intenção primeira da disciplina, o aprofundamento no estudo da natureza do fenômeno pode também ocorrer dentro da pesquisa dialetológica, isso porque há o pressuposto de que

\footnotetext{
O espaço geográfico evidencia a particularidade de cada terra, exibindo a variedade que a língua assume de uma região para outra, como forma de responder à diversidade cultural, à natureza da formação demográfica da área, à própria base linguística preexistente e à interferência de outras línguas que se tenham feito presentes naquele espaço no curso de sua história (CARDOSO, 2010:15).
}

Desta maneira, mais que a identificação, descrição e localização dos diferentes usos de uma língua, podemos (e devemos) visar a uma abordagem dialetológica que não se descuide completamente da interferência que têm os demais fatores extralinguísticos na língua - uma vez que o falante é visto como um ser geograficamente situado, mas socialmente comprometido, sendo agente, portanto, da constituição histórica de sua comunidade e de seu idioma.

O estudo atento dos objetivos e procedimentos da Dialetologia deve ainda trazer à tona a característica interdisciplinar que possui. Nesse sentido, Coseriu (1982) observa na Dialetologia uma aproximação da Gramática - isto é, do estudo das relações internas de um sistema. No entanto, a abordagem gramatical dentro da Dialetologia só terá sentido à medida que fundamente e viabilize o cotejamento das variedades dialetais, mostrando peculiaridades e semelhanças entre os dialetos. 
Por outro lado, considerando que "os dialetos são acervos preciosos onde se encontram estados da evolução ${ }^{17 "}$ linguística, Cardoso (2010) observa também a relação existente entre a Dialetologia e a Linguística Histórica. Para tanto, parte da possibilidade de relacionar a realidade linguística atual com uma anterior, valendo-se da observação de um conjunto de mudanças e transformações que ocorrem de modo próprio em cada um dos dialetos. Aparentemente, está pressuposta nessa relação o fato de os que "os grupos mais próximos ao centro são os que geralmente se mostram mais móveis ${ }^{18}$ " e inovadores, ao passo que "os que se encontram mais próximos a qualquer dos extremos tendem a ser os mais estáveis e conservadores ${ }^{19}$ ".

Uma terceira disciplina que recorrentemente se associa à Dialetologia é a Sociolinguística; isso se deve a que os dialetos são, em essência, espaços geossociais. Dessa maneira, os microssistemas inseridos na língua histórica tornam-se constructos sociais que se orientam pelas necessidades de seus falantes e que se espalham no espaço físico conforme se espalham seus usuários. É tendo em vista esse vínculo que Bustos Gisbert (2004) afirma:

[...] la dialectología no puede prescindir de la utilización de parámetros sociolingüísticos si quiere describir de forma adecuada la variación geográfica, tanto en lo que atañe a la selección de informantes, como a la interpretación de las fronteras dialectales o de los propios procesos de variación y cambio lingüístico (BUSTOS GISBERT, 2004:47) ${ }^{20}$.

De alguma maneira, a aproximação à Sociolinguística deveu-se ao aprimoramento da Geografia Linguística (ou Geolinguística), considerada um método da Dialetologia (Cardoso, 2010; Coseriu, 1977; Dubois, 1978):

\begin{abstract}
"[...] "geografía lingüística" designa exclusivamente un método dialectológico y comparativo [...] que presupone un registro en mapas especiales de un número relativamente elevado de formas lingüísticas (fónicas, léxicas o gramaticales) [...], tiene en cuenta la distribución de las formas en el espacio geográfico correspondiente a la lengua [...]" (COSERIU, 1977:103) ${ }^{21}$.
\end{abstract}

Antes, porém, de observar mais atentamente os procedimentos - isoglossa e atlas linguísticos - adotados pela Geografia Linguística para estabelecer a distribuição espacial das formas linguísticas, compete-nos melhor avaliar como esse método se estrutura e em que medida estabelece laços com a Dialetologia e com a Sociolinguística. Com este fim, Hernández Campoy (1999) lembra que a Geolinguística envolve um estudo multidisciplinar que integra a análise "da linguagem em seu contexto geográfico,

\footnotetext{
17 "[...] los dialectos son acervos preciosos en donde se encuentran estadios de la evolución [...]" (Montes Giraldo:81).

18 "[...] los grupos más cercanos al centro son los que generalmente resultan ser más móviles." (CHAMBERS; TRUDGILL, 1994:212).

19 “[...] los que se encuentran más cerca de cualquiera de los extremos tienden a ser lo más estables y conservadores." (CHAMBERS; TRUDGILL, 1994:212).

${ }^{20}<$ Tradução nossa> "[...] a Dialetologia não pode prescindir da utilização de parâmetros sociolinguísticos se quer descrever de forma adequada a variação geográfica, tanto no que tangencia a seleção de informantes, como a interpretação das fronteiras dialetais ou dos próprios processos de variação e mudança linguística" (BUSTOS GISBERT, 2004:47).

${ }^{21}<$ Tradução nossa>"[...] a 'geografia linguística' designa exclusivamente um método dialetológico e comparativo [...] que pressupõe um registro em mapas especiais de um número relativamente elevado de formas linguísticas (fônicas, léxicas ou gramaticais) [...], considera a distribuição das formas no espaço geográfico correspondente à língua [...]” (COSERIU, 1977:103).
} 
além do social e cultural ${ }^{22 \%, ~ f u n d a m e n t a n d o-s e, ~ p o r ~ i s s o, ~ e m ~ p r i n c i ́ p i o s ~ d a ~ D i a l e t o l o g i a ~}$ e da Sociolinguística. Dessa maneira,

[...] si considerar quién habla con quién, cuándo, cómo, qué y con qué fin resulta un planteamiento importante en la investigación sociolingüística, del mismo modo, considerar dónde se lleva a cabo esa operación desde un macronivel, dónde se localiza físicamente una comunidad lingüística, su interacción con otras y, a la vez, su interrelación con el comportamiento de otras comunidades en otros núcleos de población resulta de gran importancia para los estudios geolingüísticos (HERNÁNDEZ CAMPOY, 1999:71). ${ }^{23}$

Em outras palavras, a Geografia Linguística recupera e se orienta, de alguma maneira, pela preocupação com o caráter social da linguagem, buscando estabelecer um vínculo entre o espaço e o social. Assim, apesar de centrada na variação diatópica, atenta-se também ao controle de outras variáveis que interferem no uso da língua idade, gênero, escolarização, etc - "sem a busca obcecante da quantificação, mas tomando-as de forma exemplificativa e não exaustiva, de modo a complementar os próprios dados reais" (Cardoso, 2000:67).

Uma vez que a atenção dada pela Geolinguística aos traços extralinguísticos de ordem social firmou a aproximação da Dialetologia à Sociolinguística, o que antes via a dimensão espacial de forma mais estática - limitada "à representação cartográfica da

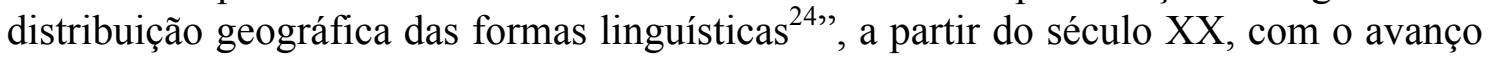
da Geolinguística, passa a reconhecer a importância de considerar mais atentamente as variáveis sociais na análise da variedade espacial, atribuindo, por consequência, maior dinamicidade à variação horizontal. Dessa maneira, a Geografia Linguística corrige os erros da teorização desligada da realidade e oferece um quadro muito mais vívido e verdadeiro da vida efetiva da linguagem (MONTES GIRALDO, 1987).

Voltando aos procedimentos mais adotados pela Geolinguística e, portanto, pela Dialetologia no cumprimento de suas tarefas, encontramos nas isoglossas (iso = igual; glossa $=$ língua) a base para a delimitação territorial dos dialetos, isto porque se trata de "linhas virtuais que marcam o limite, também virtual, de formas e expressões linguísticas" (FERREIRA; CARDOSO, 1994:12) ou, ainda, que sinalizam, na representação gráfica, a área ou domínio de vigência de uma determinada norma (MONTES GIRALDO, 1987:55). Tanto é assim que Lázaro Carreter (1968:140) define dialeto a partir da delimitação de isoglossas ao asseverar que por dialeto entende-se uma "modalidade adotada por uma língua em certo território, dentro do qual está limitada por uma série de isoglossas. A abundância destas determina a maior individualidade do dialeto $^{25}$ ".

22 “[...] del lenguaje en su contexto geográfico, además del social y cultural [...]" (HERNÁNDEZ CAMPOY, 1999:71).

${ }^{23}<$ Tradução nossa>"[...] se considerar quem fala com quem, quando, como, o que e com que fim é um questionamento importante na pesquisa sociolinguística, do mesmo modo, considerar onde se leva a cabo essa operação, a partir de um macro nível, onde se localiza fisicamente uma comunidade linguística, sua interação com outras, e, por sua vez, sua inter-relação com o comportamento de outras comunidades em outros núcleos de povoações é de grande importância para os estudos geolinguísticos" (HERNÁNDEZ CAMPOY, 1999:71).

24 "[...] a la representación cartográfica de la distribución geográfica de las formas lingüísticas [...]" (HERNÁNDEZ CAMPOY, 1999:78).

25 “[...] modalidad adoptada por una lengua en cierto territorio, dentro del cual está limitada por una serie de isoglosas. La abundancia de éstas determina una mayor individualidad del dialecto." (Lázaro Carreter, 1968:140). 
Ou seja, o feixe de isoglossas que define o dialeto corresponde a um conjunto de características que correm juntas, somando-se e mostrando uma relativa homogeneidade dentro de uma comunidade linguística. Quando em contraste com isoglossas de mesma ordem, torna possível delinear contrastes e semelhanças entre espaços geográficos. Chambers e Trudgill (1994) explicam, ainda, que a cada isoglossa corresponde um único traço linguístico e que haveria sete tipos de isoglossas, sendo a primeira classificada como mais superficial/concreta enquanto a sétima, mais profunda/abstrata:

1 - Isoglossas léxicas;

2 - Isoglossas de pronúncia;

3 - Isoglossas fonéticas;

4 - Isoglossas fonêmicas;

5 - Isoglossas morfológicas;

6 - Isoglossas sintáticas;

7 - Isoglossa

A elaboração dos mapas linguísticos, segundo procedimento metodológico muito caro à Dialetologia, orienta-se pelas já conhecidas isoglossas. Diferentemente dos atlas geográficos, os linguísticos não apresentam mapas de vários territórios, mas um conjunto de mapas que aborda individualmente a manifestação de muitos aspectos linguísticos (isoglossas) no mesmo espaço. Dessa maneira, viabiliza-se a contemplação clara e evidente da interação dos fenômenos linguísticos e da variação horizontal da língua.

Sobre os mapas linguísticos, Coseriu (1977:144) afirma possibilitarem a reflexão sobre o funcionamento da linguagem como meio de intercomunicação social, isso porque revelam a relação existente entre o comportamento histórico da língua e fatores de ordem geopolítica:

Los mapas linguísticos [...] permiten comprobar que las innovaciones en las "lenguas" proceden de ciertos centros y que su difusión se detiene en ciertos límites constituidos por ríos, montañas, fronteras políticas, administrativas o eclesiásticas (así, las zonas "aisladas" y "laterales", alejadas de los centros de innovación, suelen conservar formas lingüísticas más antiguas). Es decir, que en la distribución espacial de los hechos lingüísticos, se refleja de algún modo su cronología relativa (COSERIU, 1977:114) ${ }^{26}$.

Desta maneira, por meio da observação dos fenômenos nos atlas linguísticos, podem-se induzir, entre outros, quais são os centros de inovação e os de resistência em um território, quais mecanismos viabilizam a difusão de uma inovação, até onde alcança o raio de difusão linguística de dado centro, quais são os limites e obstáculos na propagação de um traço linguístico (COSERIU, 1977).

Por fim, retomando a classificação dos atlas linguísticos feita por Cardoso (2010), sabemos que, conforme o fenômeno observado, os atlas podem apresentar cartas onomasiológicas, isto é, que fornecem um conjunto de formas que identificam o mesmo conceito selecionado, ou cartas semasiológicas, ou seja, que reúnem diferentes conceitos para uma única forma. Por sua vez, tendo em vista o espaço avaliado nos

\footnotetext{
${ }^{26}<$ Tradução nossa>"Os mapas linguísticos [...] permitem comprovar que as inovações nas línguas procedem de certos centros e que sua difusão se detém em certos limites constituídos por rios, montanhas, fronteiras políticas, administrativas ou eclesiásticas (assim, as zonas "ilhadas", "laterais", distantes dos centros de inovação, conservam, geralmente, formas linguísticas mais antigas). Isso é, na distribuição espacial dos fatos linguísticos, reflete-se, de algum modo, sua cronologia relativa" (COSERIU, 1977:114).
} 
estudos, os atlas podem ser classificados como (a) regionais, (b) nacionais, (c) continentais e (d) de grupos linguísticos, sendo os três primeiros definidos pelos respectivos espaços geopolíticos que recobrem e o quarto, pela identificação linguística que têm os falantes de determinadas línguas; alcançando, portanto, um domínio que vai além das fronteiras políticas e assumindo uma conformação espacial própria.

\section{Em síntese...}

Diante do que expomos, julgamos que uma abordagem dialetológica deve conduzir a uma visão de língua dinâmica; não mais como um organismo autônomo, cuja vida independe dos falantes, mas como um sistema histórico e social regido pelas necessidades sócio-discursivas de seus usuários. Partindo desse princípio, entenderemos que as formas não viajam por si sós, mas trafegam pela dimensão espacial graças aos contatos traçados entre indivíduos - seja de modo direto ou indireto, como, por exemplo, pelos meios de comunicação que levam uma variedade de maior prestígio às áreas mais longínquas de uma comunidade linguística.

O prestígio atribuído a uma variedade será, portanto, um fator bastante relevante no transporte de fenômenos linguísticos, sendo este agente oriundo de diferentes motivos extralinguísticos, tais como econômicos, políticos, administrativos, culturais, religiosos, entre outros. Nesse sentido, a variedade detentora de maior prestígio irá formar um centro de irradiação, o qual não será necessariamente único, haja vista que mais de uma localidade pode apresentar dada forma prestigiada.

Tal como ressalvam Chambers e Trudgill (1994), os efeitos de uma variedade prestigiada sobre as variedades que a circunscrevem podem ser diferenciados conforme a distância guardada entre o centro e as demais zonas periféricas. Desta maneira, quanto mais próximo ao centro, maior é a tendência à inovação, ao passo que quanto mais distante, mais estabilidade e conservadorismo se encontram nas variedades. Em poucas palavras, espera-se encontrar formas mais antigas em zonas mais afastadas do centro linguístico. Finalmente, tal como adverte Coseriu (1977), não podemos nos prender unicamente à observação da heterogeneidade da língua, isto é, dos comportamentos linguísticos que variam entre os subsistemas, mas também é fundamental nos atermos aos traços que se repetem entre os dialetos de uma língua histórica.

\section{REFERÊNCIAS}

BUSTOS GISBERT, Eugenio. El espacio en la lingüística de la variación. In: CASTAÑER, Rosa María; ENGUITA, José María. Eds. Archivo de filología aragonesa: in memoriam Manuel Alvar. Vol. 2. Zaragosa: Institución Fernando el Católico, 2004

CARAVEDO, Rocío. Dialectología y sociolingüística: propuesta integradora. La torre. 7/8, p. 75-87, 1998.

CARDOSO, Suzana Alice. Geolinguística: tradição e modernidade. São Paulo: Parábola Editorial, 2010.

CHAMBERS, Jack; TRUDGILL, Peter. La dialectología. Madrid: Visor Libros, 1994.

COSERIU, Eugenio. Geografía lingüística. In: COSERIU, Eugenio. El hombre y su lenguaje. Madrid: Gredos, 1977.

COSERIU, Eugenio. Sentido y tareas de la dialectología. México: ALFAL, 1982.

DUBOIS, Jean. Dicionário de Linguística. São Paulo: Cultrix, 1978. 
FERREIRA, Carlota; CARDOSO, Suzana. A dialetologia no Brasil. São Paulo: Contexto, 1994

HERNÁNDEZ CAMPOY, Juan Manuel. La geolingüística: consideraciones sobre la dimensión espacial del lenguaje. ELUA: Estudios de Lingüística. 13, p. 65-88, 1999.

LABOV, William. Padrões Sociolinguísticos. Trad. Marcos Bagno. São Paulo: Parábola Editorial, 2008.

LÁZARO CARRETER, Fernando. Diccionario de términos filológicos. Madrid: Gredos, 1968.

LOPE BLANCH, Juan Miguel. Lengua y Dialecto/ Gramática y Dialectología. La Torre. 7/8, p. 41-47, 1998.

MONTES GIRALDO, José Joaquín. Dialectología general e hispanoamericana: Orientación teórica, metodológica y bibliográfica. Bogotá: ICC, 1987.

WEINREICH, Uriel; LABOV, William; HERZOG, Marvin. Fundamentos empíricos para uma mudança linguística. São Paulo: Parábola, 2006.

Recebido em: junho de 2020. Aprovado em: agosto de 2020.

Como citar este trabalho:

ARAUJO, L. S. de. Dialetologia: a Dimensão Espacial da Variação Linguística. Traços de Linguagem, v. 4, n. 1, p. 50-60, 2020. 